\title{
New EPMA-XRF Integration Allows Rapid Trace Element Analysis of Geological Materials
}

\author{
Rie Wakimoto $^{1}$, Takaomi Yokoyama ${ }^{1}$, Kazunori Tsukamoto ${ }^{1}$, Koki Kato ${ }^{1}$ and Vernon Robertson ${ }^{2}$ \\ ${ }^{1}$ JEOL Ltd., Akishima, Tokyo, Japan, ${ }^{2}$ JEOL.Ltd, Peabody, Massachusetts, United States
}

Electron microprobe analyzers (EPMA) is widely used for chemical analysis of solid samples such as: geological materials, metals, glasses, and biological materials. We have built on JEOL's 60 years of experience in both EPMA and SEM technology and have merged the two into a superior imaging and analytical EPMA. Due to the growing use of electron probe microanalysis in applications like geological materials, there is an increased requirement for instruments that enable fast scan rates at stable probe current conditions at the micro scale. On the other hand, XRF (X-ray fluorescence) is a non-destructive analytical technique used to determine the elemental composition of materials over a much wider area than EPMA.

Last year, JEOL developed a new "Integrated EPMA"; JXA-iSP100 / iHP200F " series that integrates WDS and EDS and also our XRF (JSX-1000S: ElementEye TM). The newly developed EPMAs have improved not only the qualitative measurement of WDS and EDS, but also the automated measurement condition setting function linked with XRF analyzed data. Advanced elemental analysis over a wide area with XRF can lead to accurate elemental identification and help setting elements for analysis with the EPMA.

Wide-area elemental analysis of basalt with a sample size of about $10 \mathrm{~mm}$ x $10 \mathrm{~mm}$ was performed using the EPMA-XRF integration system. Qualitative elemental analysis of the entire sample can be acquired with XRF. Integrated elemental maps were acquired using EDS for major elements, and using WDS for trace elements and elements that have overlapping peaks with EDS.

The major oxide composition of the basaltic rock is as follows: $\mathrm{SiO}_{2}-46.6 \%, \mathrm{Al}_{2} \mathrm{O}_{3}-17.0 \%, \mathrm{FeO}-13.8 \%$ (Fe calculated with $\mathrm{FeO}$ ), $\mathrm{MgO}-3.6 \%$, CaO-11.9\%, $\mathrm{Na}_{2} \mathrm{O}-3.3 \%, \mathrm{~K}_{2} \mathrm{O}-1.4 \%$, $\mathrm{TiO}_{2}-1.2 \%$ excluding other trace elements present in the sample. Trace amounts of $\mathrm{Y}$ at $60 \mathrm{ppm}$ and $\mathrm{Rb}$ at $45 \mathrm{ppm}$ were detected in the XRF analysis (Figure 1A).

Trace $\mathrm{Rb}$ and $\mathrm{Y}$ are difficult to separate from the large Si peak with the energy resolution of EDS (Figure 1B) because the energy of Rb La (1.69 keV) and Y La (1.92 keV) are close to the energy of Si Ka (1.74 $\mathrm{keV}$ ) and $\mathrm{P} \mathrm{Ka}(2.01 \mathrm{keV})$. The XRF tube with a voltage of $50 \mathrm{kV}$ can excite $\mathrm{Rb} \mathrm{Ka}$ at $13.37 \mathrm{keV}$ and $\mathrm{Y}$ $\mathrm{Ka}$ at $14.93 \mathrm{keV}$. These $\mathrm{K}$-emission peaks of $\mathrm{Rb}$ and $\mathrm{Y}$ (and also $\mathrm{Zr}$ and $\mathrm{Sr}$ ), are clearly identifying using EDS-XRF (Figure 1C). Figure 2 shows the backscattered electron image (BSE) of the area analyzed with XRF and WDS map results for Y overlaid on the BSE image. The WDS stage maps show that Y is located in the microstructure of glass matrix area of about $100 \mu \mathrm{m}$ or less. The combination of quick and easy XRF wide area element screening with EPMA has enabled rapid analysis of the microstructure and trace element distribution in geological materials. 


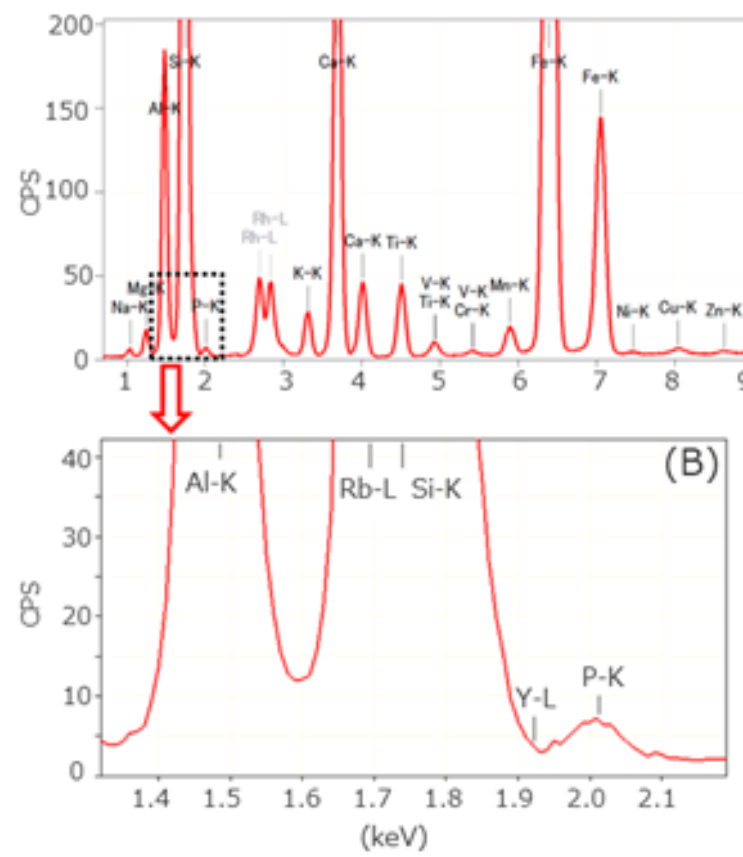

\section{(A)}

Figure 1. XRF spectrum of a basaltic rock. (A) Whole energy range. (B) Enlarged 1.3-2.2 keV. (C) Enlarged 13-19 keV.

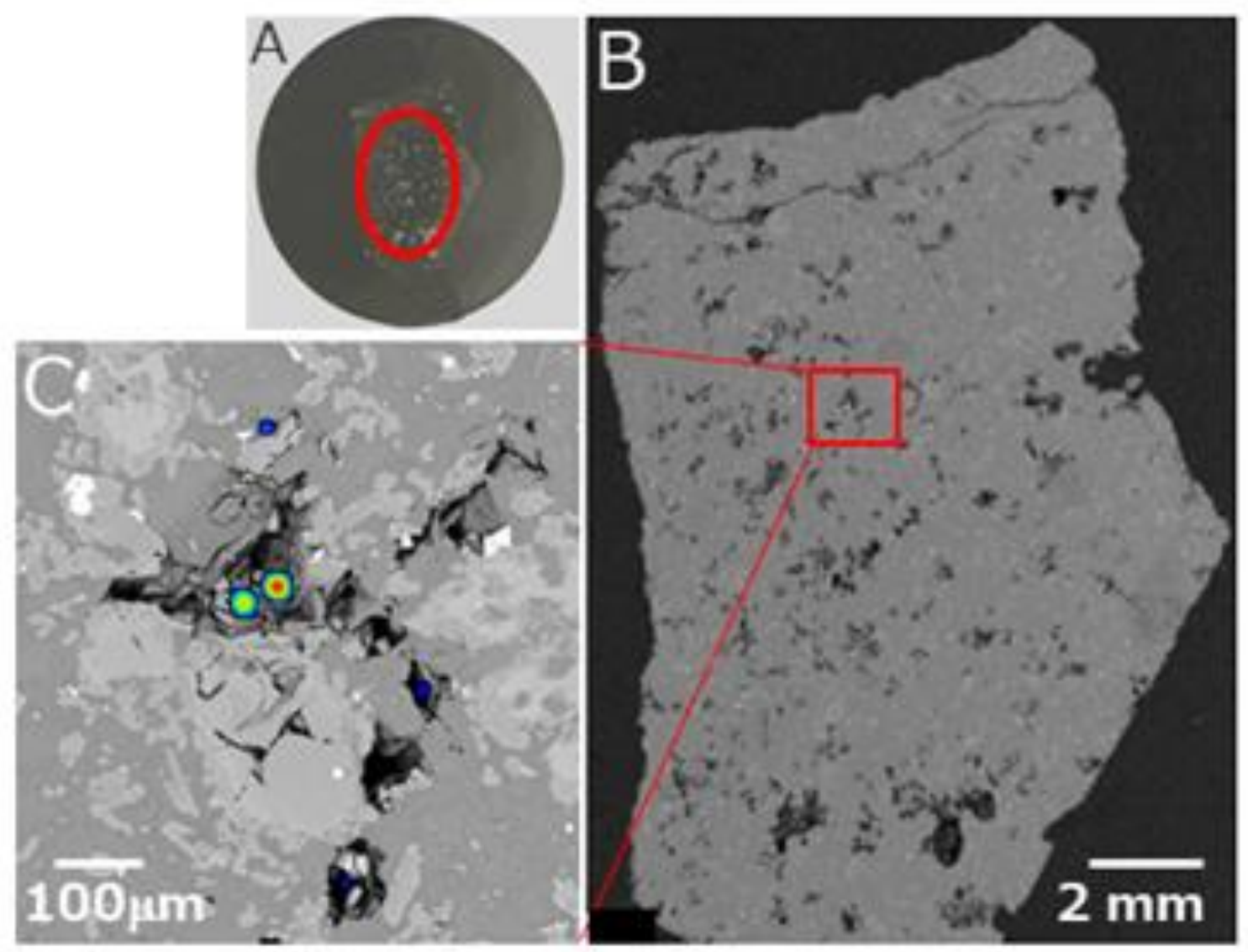

Figure 2. XRF and WDS analysis of basaltic rock. A BSE image of basaltic rock (A) Overlay of WDS elemental map of Y (B) and (C). 